\title{
Polymorphism of CYP3A4 and ABCBI genes increase the risk of neuropathy in breast cancer patients treated with paclitaxel and docetaxel
}

\author{
Tulay Kus' \\ Gokmen Aktas' \\ Mehmet Emin Kalender ${ }^{\prime}$ \\ Abdullah Tuncay \\ Demiryurek ${ }^{2}$ \\ Mustafa Ulasli' \\ Serdar Oztuzcu ${ }^{3}$ \\ Alper Sevinc' \\ Seval Kul ${ }^{4}$ \\ Celaletdin Camci ${ }^{1}$ \\ 'Department of Internal Medicine, \\ Division of Medical Oncology, \\ University of Gaziantep, Gaziantep \\ Oncology Hospital, Gaziantep, \\ Turkey; ${ }^{2}$ Department of Medical \\ Pharmacology, ${ }^{3}$ Department of \\ Medical Biology, Faculty of Medicine, \\ University of Gaziantep, Gaziantep, \\ Turkey; ${ }^{4}$ Department of Biostatistics, \\ Faculty of Medicine, University of \\ Gaziantep, Gaziantep, Turkey
}

This article was published in the following Dove Press journal:

OncoTargets and Therapy

12 August 2016

Number of times this article has been viewed

Background: Interindividual variability of pharmacogenetics may account for unpredictable neurotoxicities of taxanes.

Methods: From March 2011 to June 2015, female patients with operable breast cancer who had received docetaxel- or paclitaxel-containing adjuvant chemotherapy were included in this study. All patients were treated with single-agent paclitaxel intravenously (IV) $175 \mathrm{mg} / \mathrm{m}^{2}$ every 3 weeks for four cycles, or IV $80 \mathrm{mg} / \mathrm{m}^{2}$ weekly for 12 cycles, and IV $100 \mathrm{mg} / \mathrm{m}^{2}$ docetaxel for four cycles as adjuvant treatment. We evaluated the relationship between neurotoxicity of taxanes and single-nucleotide polymorphisms of $A B C B 1, C Y P 3 A 4, E R C C 1, E R C C 2, F G F R 4, T P 53$, $E R B B 2$, and $C Y P 2 C 8$ genes. Taxane-induced neurotoxicity during the treatment was evaluated according to the National Cancer Institute Common Toxicity Criteria version 4.03 prior to each cycle. Chi-squared tests were used to compare the two groups, and multivariate binary logistic regression models were used for determining possible risk factors of neuropathy.

Results: Pharmacogenetic analysis was performed in 219 females. ABCB1 3435 TT genotype had significantly higher risk for grade $\geq 2$ neurotoxicity (odds ratio [OR]: $2.759,95 \%$ confidence interval [CI]: 1.172-6.493, $P$ : 0.017) compared to TC and CC genotype, and also CYP3A4 392 AA and AG genotype had significantly higher risk for grade $\geq 2$ neurotoxicity (OR: 2.259 , 95\% CI: 1.033-4.941, P: 0.038) compared to GG genotype. For FDGF4 gene with AG and GG genotype, OR was 1.879 (95\% CI: 1.001-3.525, P: 0.048) compared to AA genotype with regard to any grade of neuropathy risk. We could not find any other association of other genotypes with neurotoxicity grades.

Conclusion: $A B C B 13435$ TT genotype and CYP3A4 392 AA/AG genotypes may be used as predictors of neurotoxicity during taxane chemotherapy.

Keywords: neurotoxicity, docetaxel, paclitaxel, CYP3A4, ABCB1, single nucleotide polymorphisms

\section{Introduction}

Influence of pharmacogenetic polymorphisms on drug pharmacokinetics and pharmacodynamics has been assessed in a large number of studies. ${ }^{1-3}$ Interindividual variability in drug efficacy via metabolism and excretion could result in unpredictable treatment responses and toxicity. The potential effect of interindividual variability on these clinical variables was also conducted in several studies. ${ }^{4,5}$

Taxanes are one of the most active agents in the adjuvant and metastatic treatment of breast cancer. However, variability in toxicity and response remains a major problem for patients receiving taxanes. Significant variability of about four- to tenfold in paclitaxel clearance may contribute to the different clinical outcomes. ${ }^{3}$
Department of Internal Medicine, Division of Medical Oncology, University of Gaziantep, Gaziantep Oncology Hospital, TR-27310 Gaziantep, Turkey Email drtulaykus83@hotmail.com 
The cellular toxicity and activity of taxanes are likely controlled by multiple genes. Genes involved in transport through hepatobiliary and intestinal secretion of the parent drug by the adenosine triphosphate-binding cassette (ABC) genes, $\mathrm{ABCB} 1, \mathrm{ABCC} 1$, and $\mathrm{ABCC} 2$ isoforms; metabolism by the cytochrome P450 (CYP), CYP2C8, CYP3A4, and CYP3A5 isoforms; and pharmacodynamics by TP53 and CDKN1A genes, all appear to play a role in taxane efficacy and toxicity. In addition, DNA damage repair genes (eg, ERCC1-2 [excision repair cross complementation]) may contribute to this process. ${ }^{6-8}$

The metabolism of taxanes consists of a CYP3A-mediated oxidation; docetaxel is predominantly metabolized by CYP3A4/5, whereas paclitaxel is metabolized by CYP2C8/ CYP3A4 to inactive hydroxylated metabolites. ${ }^{9,10}$ Elimination pathway of taxanes is mediated by the membranelocalized, energy-dependent drug efflux ABC transporter, P-glycoprotein (P-gp), which has been described in several polymorphisms. ${ }^{11}$ The percentage of tumors expressing P-gp in breast cancer was $41.2 \%$, and its expression rate increases after chemotherapy, which could result in failure of treatment. ${ }^{12}$ It was reported that there is a possible relationship between single-nucleotide polymorphisms (SNPs) of the $A B C B 1$ gene, which affect the activity of P-gp, and the clinical outcome and toxicity of patients who were treated with taxane..$^{13,14}$

Toxicities of taxanes, such as neuropathy, neutropenia, infusion-related reactions, and mucositis, causing interruption, dose reduction, or treatment modification, were evaluated for possible relationship with pharmacogenetic polymorphisms in some studies. ${ }^{15,16}$ Taxane-induced neurotoxicity is mostly presented as a sensorial component, especially at the cumulative doses of drugs that breast cancer patients receive in the adjuvant setting. Accordingly, we evaluated whether ABCB1 3435C $>$ T, CYP3A4 392A $>\mathrm{G}$, ERCC1 $60312 \mathrm{~A}>\mathrm{G}$, ERCC2 $2251 \mathrm{~A}>\mathrm{C}$, fibroblast growth factor receptor 4 (FGFR4) 176520243 G $>$ A, TP53 7579472 $\mathrm{G}>\mathrm{C}$, ERBB2 $1873 \mathrm{~A}>\mathrm{G}$, and CYP2C8 $35707 \mathrm{G}>\mathrm{A}$ polymorphisms have any effect on neuropathy risk in breast cancer patients treated with taxane in adjuvant setting.

\section{Patients and methods Study design}

This retrospective study was conducted in Gaziantep University Oncology Hospital in Turkey. The study and written informed consent documentation were reviewed and approved by the Independent Ethics Committee of Gaziantep University, Medical Faculty. This study was conducted in compliance with the ethical principles according to the
Declaration of Helsinki. The trial was designed to assess whether pharmacogenetic differences influence taxaneinduced neurotoxicity.

\section{Patient selection and genotypes}

In total, 219 female breast cancer patients who underwent operation and received adjuvant taxane chemotherapy were enrolled, and pharmacogenetic analysis was carried out using the peripheral blood sample. Five-milliliter blood samples were collected in sterile-siliconized vacuum tubes with $2 \mathrm{mg} / \mathrm{mL}$ disodium EDTA. Immediately, genomic DNA was extracted from whole blood. Genetic variants of rs1045642 at chromosome (chr)7: 87138645 in ABCB1: C3435T minor allele frequency (MAF): $\mathrm{A}=0.3952 / 1,979$, rs2740574 at chr7: 99784473 in CYP3A4: 392A $>$ G (CYP3A4*1B) MAF: $C=0.2308 / 1,156$, rs3212935 at chr19: 45926775 in ERCC1: $60312 \mathrm{~A}>\mathrm{G}$ MAF $: \mathrm{C}=0.1026 / 514$, rs 13181 at chr19: 45854919 in ERCC2: $2251 \mathrm{~A}>\mathrm{C}$ MAF: $\mathrm{G}=0.2366 / 1,185$, rs351855 at chr5: 176520243 in FGFR4: $176520243 \mathrm{G}>\mathrm{A}$ MAF: $A=0.2995 / 1,500$, rs 1042522 at chr17: 7579472 in TP53: $7579472 \mathrm{G}>\mathrm{C}$ MAF: $\mathrm{G}=0.4571 / 2,289$, rs1136201 at chr17: 37879588 in ERBB2: $1873 \mathrm{~A}>\mathrm{GMAF}: \mathrm{G}=0.1214 / 608$, rs1934951 at chr10: 96798548 in CYP2C8: $35707 \mathrm{G}>\mathrm{A}$ MAF: $T=0.2997 / 1,501$ were studied by genotyping using the Fluidigm Digital Array (Fluidigm, South San Francisco, CA, USA). These polymorphisms were evaluated by using genomic DNA a 96.96 dynamic array on the BioMark HD System (Fluidigm). Dose, schedule, and duration of chemotherapy were noted. All patients had a diagnosis of breast carcinoma and were treated with single-agent paclitaxel intravenously (IV) $175 \mathrm{mg} / \mathrm{m}^{2}$ per 3 weeks for four cycles, or IV $80 \mathrm{mg} / \mathrm{m}^{2}$ weekly for 12 cycles, and IV $100 \mathrm{mg} / \mathrm{m}^{2}$ docetaxel for four cycles. Some patients received additional biologic treatment concurrent with the taxane, such as the Her-2targeted therapy for the subset of Her-2-overexpressing tumors. Patients without diabetes mellitus (DM) and patients with duration of DM $<5$ years were evaluated as low-risk patients for neuropathy. Duration of DM $>5$ years and age $\geq 65$ years were evaluated as risk factors for neurotoxicity and were separately analyzed. Patients were divided into two groups: patients with neurotoxicity and those without. Grade $<2$ neurotoxicity and grade $\geq 2$ neurotoxicity were also separately assessed.

Inclusion criteria were as follows: patients $>18$ years of age, both sexes, Eastern Cooperative Oncology Group performance status of $0-1$, histologically proven breast cancer, and receiving paclitaxel or docetaxel regimen.

Exclusion criteria were as follows: patients with brain or leptomeningeal metastasis, previous platinum-based 
or neurotoxic chemotherapy, history of alcohol dependency or concurrent use of other drugs known to influence serotonin levels, DM with preexisting neuropathy, unstable psychological conditions, use of antiepileptics, antidepressants, or lithium, and use of opioids (concomitant use of selected analgesics like nonsteroidal anti-inflammatory drugs was allowed).

\section{Assessment of neurotoxicity}

Diagnosis of taxane-induced peripheral neurotoxicity was evaluated based on symptom history, loss of deep tendon reflexes, and the presence of symmetrical "stocking-glove" numbness and burning-tingling after chemotherapy. Baseline taxane-induced peripheral neurotoxicity was assessed according to the National Cancer Institute Common Toxicity Criteria for Adverse Events version 4.03 grading scale $(0=$ normal, $1=$ asymptomatic, weakness on physical examination, loss of reflexes, or paresthesias not interfering with daily function, $2=$ weakness and sensory alterations interfering with daily function, $3=$ weakness and sensory alterations interfering with activities of daily living or requiring bracing or assistive devices, and $4=$ life threatening, paralysis, disabling). Pretreatment evaluation for the patients who developed acute neurotoxicity was based on the tenquestion form of the Neuropathic Pain Symptom Inventory and National Cancer Institute Common Toxicity Criteria for Adverse Events v 4.03 prior to each cycle of chemotherapy. Questions related to burning, squeezing, pressure, electric shocks, stabbing, evoked by brushing, evoked by pressure, pins and needles, and tingling were asked.

\section{Statistical analysis}

First, univariate analyses were performed to compare the two groups: chi-squared tests were used for categorical variables and univariate binary logistic regression method was used for estimating odds ratios (ORs) and 95\% confidence interval (CI). Second, multivariate binary logistic regression models were used for adjusting confounding factors while determining possible risk factors. Multicollinearity was checked by calculating variance inflation factors. All univariate analyses were performed using SPSS for Windows, version 22.0 (IBM Corporation, Armonk, NY, USA). A two-sided $P$-value $<0.05$ was considered statistically significant.

Posterior power analysis was performed based on significant effects of $C Y P 3 A 4$ and $A B C B 1$ genes on grade $\geq 2$ neuropathy. Posterior power values were found to be $65 \%$ for CYP3A4 (effect size: 0.22 vs 0.10 ) and $48 \%$ for ABCB1 (effect size: 0.32 vs 0.15 ), when Type I error rate was 0.05 .

\section{Results}

Two-hundred and nineteen breast cancer patients who were operated on and received adjuvant taxane chemotherapy were enrolled in this study. Of these patients, 55 (25.1\%), 129 (58.9\%, and $35(15.9 \%)$ patients received weekly paclitaxel, docetaxel for 3 weeks, and paclitaxel for 3 weeks, respectively. Fifty one (23.3\%) patients had DM. Approximately 116 (53\%) patients experienced neurotoxicity. Sixty-four (62.1\%) of these patients had Grade 1, 33 (32\%) had Grade 2, and six (5.8\%) patients had Grade 3 neurotoxicity. Two-hundred and eight patients were under the age of 65 years and eleven patients were over the age of 65 years. Neurotoxicity development and grading are summarized in Table 1 regarding age, status of DM, and receiving taxane chemotherapy type. Distribution of genetic polymorphism according to risk factors is listed in Table 2. Patient characteristics are summarized in Table 3.

\section{According to pharmacogenotype}

Genotypes of all genes and frequencies of variance according to age, duration of DM, and type of taxane chemotherapy are

Table I Neuropathy risks of patients according to DM status, type of drug, and age

\begin{tabular}{|c|c|c|c|c|c|c|c|}
\hline Variables & $\mathbf{N}(\%)$ & $\begin{array}{l}\text { Neuropathy } \\
\text { have/none (n) }\end{array}$ & $P$-value & OR (95\% Cl) & $\begin{array}{l}\text { Neuropathy } \geq \text { grade } 2 \\
\text { have/none }(n)\end{array}$ & $P$-value & OR $(95 \% \mathrm{CI})$ \\
\hline \multicolumn{8}{|l|}{ DM status } \\
\hline No DM and DM $<5$ years & $199(90.9)$ & $90 / 109$ & 0.091 & $0.44(0.17-1.16)$ & $30 / 169$ & 0.001 & $4.6(1.76-12.07)$ \\
\hline $\mathrm{DM} \geq 5$ years & $20(9.1)$ & $13 / 7$ & & 1 & $9 / 11$ & & 1 \\
\hline \multicolumn{8}{|l|}{ Taxane type } \\
\hline Paclitaxel $^{\mathrm{a}}$ & $55(25.1)$ & $29 / 26$ & 0.618 & & $10 / 45$ & & \\
\hline Docetaxel & $129(58.9)$ & $58 / 71$ & & & $22 / 107$ & 0.918 & \\
\hline Paclitaxel $^{\mathrm{b}}$ & $35(16)$ & $16 / 19$ & & & $7 / 28$ & & \\
\hline \multicolumn{8}{|l|}{ Age, years } \\
\hline$<65$ & $208(95)$ & $97 / 111$ & 0.608 & $0.72(0.2 \mathrm{I}-2.46)$ & $170 / 38$ & 0.438 & $0.44(0.056-3.60)$ \\
\hline$\geq 65$ & II (5) & $6 / 5$ & & 1 & $10 / 1$ & & I \\
\hline
\end{tabular}

Notes: ${ }^{a}$ Weekly, ${ }^{b}$ thrice weekly.

Abbreviations: $\mathrm{OR}$, odds ratio; $\mathrm{DM}$, diabetes mellitus; $\mathrm{Cl}$, confidence interval; $\mathrm{N}$, number of patients. 
Table 2 Distribution of genetic polymorphism according to risk factors

\begin{tabular}{|c|c|c|c|c|c|c|}
\hline Gene & SNP & Genotype & $\mathbf{N}(\%)$ & $\begin{array}{l}\text { Received paclitaxel } \\
\text { vs docetaxel } \\
P \text {-value }\end{array}$ & $\begin{array}{l}\text { Age }<65 \text { vs } \\
\geq 65 \text { (years) } \\
P \text {-value }\end{array}$ & $\begin{array}{l}\text { No } D M \text { and } D M<5 \text { years } \\
\text { vs } D M \geq 5 \text { years } \\
P \text {-value }\end{array}$ \\
\hline \multirow[t]{3}{*}{ CYP3A4 } & rs 2740574 & GG & $92(42.0)$ & 0.643 & 0.619 & 0.555 \\
\hline & & AG & II (5.0) & & & \\
\hline & & $\mathrm{AA}$ & II4 (52.I) & & & \\
\hline \multirow[t]{3}{*}{ CYP2C8 ${ }^{\circ}$} & rsI93495I & AA & $5(5.6)$ & 0.984 & 0.633 & 0.922 \\
\hline & & AG & $11(12.4)$ & & & \\
\hline & & GG & $73(82)$ & & & \\
\hline \multirow[t]{3}{*}{$A B C B I$} & rs 1045642 & $\mathrm{CC}$ & $30(13.7)$ & 0.421 & 0.208 & 0.876 \\
\hline & & $\mathrm{CT}$ & $159(72.6)$ & & & \\
\hline & & $\mathrm{TT}$ & $30(13.7)$ & & & \\
\hline \multirow[t]{3}{*}{$E R C C I$} & rs3212935 & AA & $195(89)$ & 0.119 & 0.689 & 0.968 \\
\hline & & AG & $9(4.1)$ & & & \\
\hline & & GG & $12(5.5)$ & & & \\
\hline \multirow[t]{3}{*}{$E R C C 2$} & rs|3|8I & AA & $43(19.6)$ & 0.572 & 0.734 & 0.090 \\
\hline & & $A C$ & $122(55.7)$ & & & \\
\hline & & $\mathrm{CC}$ & $25(I I .4)$ & & & \\
\hline \multirow[t]{3}{*}{ ERBB2 } & rsII3620I & AA & $192(89.7)$ & 0.44 & 0.283 & 0.848 \\
\hline & & AG & $15(7.0)$ & & & \\
\hline & & GG & $7(3.3)$ & & & \\
\hline \multirow[t]{3}{*}{ P53 } & rs 1042522 & $\mathrm{CC}$ & $27(12.3)$ & 0.344 & 0.666 & 0.885 \\
\hline & & GC & $4 \mid(18.7)$ & & & \\
\hline & & GG & $138(63.0)$ & & & \\
\hline \multirow[t]{3}{*}{ FDGFR } & rs35I855 & AA & $53(24.2)$ & 0.132 & 0.856 & 0.505 \\
\hline & & AG & $49(22.4)$ & & & \\
\hline & & GG & $\mathrm{I} \mid 2(5 \mathrm{I} . \mathrm{I})$ & & & \\
\hline
\end{tabular}

Note: alt was studied only for patients who received paclitaxel.

Abbreviations: SNP, single-nucleotide polymorphism; DM, diabetes mellitus.

listed in Table 2 (for all groups $P>0.05$ ). OR of neuropathy risk and grade $\geq 2$ neuropathy and risk according to gene SNPs are summarized in Table 4.

CYP3A4 genes were divided into two groups: GG genotype vs AA/AG genotypes. OR for any grade neuropathy was

Table 3 Patients' characteristics

\begin{tabular}{ll}
\hline Characteristic & $\mathbf{N}(\%)$ \\
\hline $\begin{array}{l}\text { Age, years } \\
\quad \text { Median (min-max) }\end{array}$ & \\
Pathology & $49.1(2$ I-79) \\
$\quad$ Invasive ductal carcinoma & $146(66.6)$ \\
$\quad$ Invasive lobular carcinoma & $24(10.9)$ \\
Other & $49(22.3)$ \\
Stage & \\
I & $28(13)$ \\
II & $136(62)$ \\
III & $83(25)$ \\
Menopause & \\
Premenopause & $98(45)$ \\
Postmenopause & 12 I (55) \\
Previous treatment & $76(35)$ \\
FEC/FAC & \\
AC/EC & $143(65)$ \\
\hline
\end{tabular}

Notes: ${ }^{\mathrm{F} E C C}$ : 5 -fluorouracil $600 \mathrm{mg} / \mathrm{m}^{2}$, epirubicin $100 \mathrm{mg} / \mathrm{m}^{2}$, and cyclophosphamide $600 \mathrm{mg} / \mathrm{m}^{2}$, every 2 I days $/ \mathrm{FAC}$ : 5 -fluorouracil $500 \mathrm{mg} / \mathrm{m}^{2}$, doxorubicin $50 \mathrm{mg} / \mathrm{m}^{2}$, and cyclophosphamide $500 \mathrm{mg} / \mathrm{m}^{2}$, every 21 days. ${ }^{b} \mathrm{AC}$ : cyclophosphamide $600 \mathrm{mg} / \mathrm{m}^{2}$, doxorubicin $60 \mathrm{mg} / \mathrm{m}^{2}$ every 21 days $/ E C$ : cyclophosphamide $600 \mathrm{mg} / \mathrm{m}^{2}$, epirubicin $90 \mathrm{mg} / \mathrm{m}^{2}$ every 21 days.
0.64 (95\% CI: 0.37-1.10, P: 0.109), and OR for $>$ Grade 1 neuropathy was 2.26 (95\% CI: $1.03-4.94, P: 0.038)$ in favor of AA/AG genotype.

CYP2C8 genes were divided into two groups: GG genotype vs AA and AG genotypes. It was evaluated only for the paclitaxel group. OR for any grade neuropathy was 0.97 (95\% CI: 0.33-2.87, P: 0.960), and OR for $>$ Grade 1 neuropathy was 0.65 (95\% CI: 0.18-2.34, $P$ : 0.507).

$A B C B 1$ genes were divided into two groups: $\mathrm{CC} / \mathrm{CT}$ vs TT genotypes. OR for any grade neuropathy was $0.64(95 \%$ CI: $0.29-1.39, P$ : 0.255$)$, and OR for $>$ Grade 1 neuropathy was $2.76(95 \% \mathrm{CI}: 1.17-6.49, P: 0.017)$ in favor of TT genotype.

ERCC 1 genes were divided into two groups: AA vs AG and GG genotype. OR for any grade neuropathy was 0.96 (95\% CI: 0.39-2.37, $P$ : 0.934), and OR for $>$ Grade 1 neuropathy was 1.15 (95\% CI: 0.365-3.654, $P$ : 0.806).

ERCC2 genes were divided into two groups: AA vs AC and CC genotypes. OR for any grade neuropathy was 1.01 (95\% CI: 0.51-1.99, $P$ : 0.977), and OR for $>$ Grade 1 neuropathy was 0.55 (95\% CI: $0.24-1.28, P: 0.161)$.

$E R B B 2$ genes were divided into two groups: AA vs AG and GG genotypes. OR for any grade neuropathy was 
Table 4 ORs of neuropathy risk and grade $\geq 2$ neuropathy risk according to genotypes

\begin{tabular}{|c|c|c|c|c|c|c|}
\hline \multirow[t]{2}{*}{ Gene } & \multirow[t]{2}{*}{ Genotype } & \multirow[t]{2}{*}{$\mathbf{N}$} & \multicolumn{2}{|l|}{ Neuropathy risk } & \multicolumn{2}{|c|}{ Grade $\geq 2$ neuropathy risk } \\
\hline & & & OR (95\% Cl) & Significance & OR (95\% Cl) & Significance \\
\hline \multirow[t]{2}{*}{ CYP3A4 } & GG vs & 217 & 1 & & 1 & \\
\hline & $A A$ and $A G$ & & $0.64 I(0.37-1.10)$ & 0.109 & $2.259(1.03-4.94)$ & 0.038 \\
\hline \multirow[t]{2}{*}{ CYP2C8 } & $A A$ and $A G$ vs & 89 & 1 & 0.960 & 1 & \\
\hline & GG & & $0.973(0.33-2.87)$ & & $0.650(0.18-2.34)$ & 0.507 \\
\hline \multirow[t]{2}{*}{$A B C B I$} & $C C$ and $C T$ vs & 219 & 1 & 0.255 & 1 & \\
\hline & TT & & $0.638(0.29-1.39)$ & & $2.759(1.17-6.49)$ & 0.017 \\
\hline \multirow[t]{2}{*}{ ERCCI } & AA vs & 216 & 1 & 0.934 & 1 & \\
\hline & $A G$ and $G G$ & & $0.962(0.39-2.37)$ & & I.I555 (0.36-3.65) & 0.806 \\
\hline \multirow[t]{2}{*}{ ERCC2 } & AA vs & 190 & 1 & 0.977 & 1 & \\
\hline & $A C$ and $C C$ & & $1.010(0.511-1.99)$ & & $0.550(0.24-1.28)$ & 0.161 \\
\hline \multirow[t]{2}{*}{ ERBB2 } & $A A$ vs & 214 & 1 & 0.710 & 1 & \\
\hline & $A G$ and $G G$ & & $0.846(0.35-2.04)$ & & $1.528(0.52-4.45)$ & 0.437 \\
\hline \multirow[t]{2}{*}{ P53 } & CC vs & 206 & 1 & 0.244 & 1 & \\
\hline & GC and GG & & $1.619(0.72-3.65)$ & & $0.705(0.26-1.89)$ & 0.486 \\
\hline \multirow[t]{2}{*}{ FDGFR } & AA vs & 214 & 1 & 0.048 & 1 & \\
\hline & $A G$ and $G G$ & & $1.879(1.00-3.52)$ & & $0.628(0.29-1.36)$ & 0.234 \\
\hline
\end{tabular}

Notes: A two-sided $P$-value $<0.05$ was considered statistically significant. Chi-squared test was used.

Abbreviations: $\mathrm{OR}$, odds ratio; $\mathrm{Cl}$, confidence interval.

0.85 (95\% CI: $0.35-2.04, P: 0.710)$, and OR for $>$ Grade 1 neuropathy was 1.53 (95\% CI: 0.52-4.45, $P: 0.437)$.

$P 53$ genes were divided into two groups: $\mathrm{CC}$ vs $\mathrm{CG}$ and GG genotypes. OR for any grade neuropathy was 1.62 (95\% CI: $0.72-3.65, P: 0.244)$, and OR for $>$ Grade 1 neuropathy was 0.70 (95\% CI: $0.26-1.89, P: 0.486)$.

FDGFR genes were divided into two groups: AA vs $\mathrm{AG}$ and $\mathrm{GG}$ genotypes. OR for any grade neuropathy was 1.88 (95\% CI: $1.00-3.52, P: 0.048$ ), and OR for $>$ Grade 1 neuropathy was $0.63(95 \% \mathrm{CI}: 0.29-1.36, P: 0.234)$ in favor of AG/GG genotype.

According to multivariate analysis, after adjusting for status of DM, CYP3A4 had an OR of 4.64 (95\% CI: 1.08-5.50, $P: 0.001)$ for $>$ Grade 1 neuropathy. The OR was $5.47(95 \%$ CI: 1.17-6.94, $P: 0.019)$ for ABCB1.

\section{Discussion}

Taxanes produce a symmetric, axonal, predominantly sensory distal neuropathy with less prominent motor involvement, and more than $50 \%$ of patients experience varied degree of sensory peripheral neuropathy during their course of taxane treatment, with approximately $5 \%-30 \%$ having Grade 3 or 4 toxicity. ${ }^{17,18}$ Sensorial neuropathy typically manifests as tingling-burning, stabbing, and pins and needles in the distal extremities, leading to loss of sensation, which may progress to loss of function that can be irreversible if treatment is continued; thus, taxane therapy is often discontinued once the patient experiences neurotoxicity over Grade 2. Taxane-induced sensorial neuropathy is associated with dose per cycle, treatment schedule, duration of infusion, cumulative dose, comorbidity, age $(<65$ vs $>65$ years), prior or concomitant administration of platinum compounds or vinca alcaloids, preexisting peripheral neuropathy, paraneoplastic syndromes, duration of DM, alcohol abuse, and also pharmacogenetic polymorphisms on taxane pharmacokinetics. ${ }^{19-23}$

Despite the considerable clinical activity of taxanes in various cancer types, variability in toxicity, unpredictability of clinical outcomes, and different responses to the treatment remain major problems. Numerous pharmacogenetic studies focused on the contribution of genetic variations to these interindividual differences in the patients receiving taxane therapy. The goal of this study was to identify pharmacogenetic polymorphisms that may be predictive to sensory peripheral neuropathy in patients receiving taxanes in adjuvant setting. We showed that polymorphisms in the $C Y P 3 A 4$ and $A B C B 1$ genes are able to predict taxane neurotoxicity.

SNPs in $C Y P 450$ and $A B C B 1$ genes are primarily responsible for taxane metabolism, which probably has an effect on the varying response. Although the relationship between pharmacogenetic variations of these polymorphisms and recurrence risk of early-stage breast cancer did not emerge, longer progression-free survival in local-advanced and metastatic setting was indicated in some studies. ${ }^{24,25}$ It was found that TT genotype of ABCB1 C3435T was correlated with reduced expression of $\mathrm{P}$-gp; thus, it reduced cellular elimination and maintained higher plasma concentrations of drugs. ${ }^{26}$ A study showed that the TT genotype of $A B C B 13435$ was associated with a higher plasma concentration of docetaxel 
and longer overall survival. However, this was statistically insignificant in patients treated in a neoadjuvant setting (hazard ratio [HR]: $0.69,95 \% \mathrm{CI}: 0.33-1.26, P$ : 0.126$)$. In addition, $A B C B 1$ 3435TT genotype caused more frequent Grade 3-4 neutropenia, febrile neutropenia, and diarrhea. ${ }^{27}$

Studies performed on pharmacogenetic polymorphism on the individual differences of taxane neurotoxicity are still inconclusive and are not enough to create a general perception. SNPs in the CYP2C8*3 gene (rs11572080 and rs10509681), which decreases paclitaxel metabolic activity, lead to increased drug exposure and are associated with potential increases in neuropathy risk. ${ }^{28,29}$ Hertz et $\mathrm{al}^{30}$ evaluated the reflection of the aforementioned gene to clinical outcomes and toxicity of 111 breast cancer patients. It was found that patients carrying the CYP2C $8 * 3$ allele obtained more clinically complete response with neoadjuvant paclitaxel (55\% vs 23\%; OR: 3.92, 95\% CI: 1.46-10.48, corrected $P: 0.046)$ but tended to have higher incidence of $>$ Grade 2 neuropathy ( $22 \%$ vs $8 \%$; OR: 3.13 , 95\% CI: 0.89-11.01, uncorrected $P$ : 0.075). Reanalysis of this study revealed that neuropathy seemed to be similar in both European-American and African-American patient cohorts. ${ }^{24,30}$ In addition, Leskela et $\mathrm{al}^{31}$ designed a study that evaluated 13 relevant polymorphisms in genes encoding paclitaxel metabolizing enzymes (CYP2C8, CYP3A4, and $C Y P 3 A 5$ ) and transporters (organic anion transporting polypeptide [OATP] 1B1, OATP1B3, and P-gp) in 118 Spanish cancer patients treated with paclitaxel. It was observed that CYP2C8 haplotype $\mathrm{C}$ and CYP3A $5 * 3$ were associated with decreased neuropathy risk (HR [per allele]: 0.55, 95\% CI: 0.34-0.89, P: 0.014 and HR: 0.51, 95\% CI: 0.30-0.86; and $P: 0.012$, respectively) and only being homozygous for the CYP2C8*3 allele was associated with increased neuropathy risk (HR: 1.72, 95\% CI: 1.05-2.82; and P: 0.032). CYP3A4 was not associated with neuropathy, unlike in our study. ${ }^{31}$ In our study, 89 patients received paclitaxel chemotherapy, and there was no statistically significant relationship between the neurotoxicity and polymorphism of CYP2C8: 35707G. A with GG genotype (OR: 0.97, 95\% CI: 0.33-2.87) for neurotoxicity compared to GA and AA genotype $(P: 0.96)$ and it was 0.65 (95\% CI: 0.18-2.34 when evaluated according to grade $P: 0.507)$.

Bosó et $\mathrm{al}^{32}$ assessed a panel with 47 SNPs in 20 genes involved in taxane pathways (including CYP1B1, CYP2C8, CYP3A4-5, ABCB1-2, TP53, and ERCC1-2) on 113 female breast cancer patients taking docetaxel and paclitaxel. It was shown that two SNPs in two genes were associated with docetaxel toxicity $(P \leq 0.01)$ (CYP3A4: infusion-related reactions, ERCC1: mucositis) and three SNPs in two different genes were associated with paclitaxel toxicity (CYP2C8: anemia; ERCC1: neuropathy, $P \leq 0.01)$. Unlike in our study, ABCB1 (rs1045642) and CYP3A4 (rs2740574) were assessed, but it was not found to be related with taxane neurotoxicity. In our study, we evaluated ERCC1: 60312A>G (rs3212935), but a relationship with neurotoxicity was not observed (OR: 1.15, 95\% CI: 0.36-3.65, P: 0.806).

Graan et $\mathrm{al}^{33}$ assessed the CYP3A4*22, CYP2C8*3, CYP2C8*4, and ABCB1 $3435 \mathrm{C}>\mathrm{T}$ genes for neuropathy in 239 patients receiving paclitaxel for various cancer types. Accordingly, CYP3A4*22 carriers had increased risk of developing severe neurotoxicity during paclitaxel therapy $(P: 0.043)$ in the exploratory cohort analysis, and CYP3A4*22 carriers were also at risk of developing Grade 3 neurotoxicity (OR: 19.1, P: 0.001), which was consistent with the results of our study. ${ }^{33}$ Additionally, another study showed that overpresentation of defective CYP3A4 variants was associated with the high-grade paclitaxel-induced neuropathy in patients receiving paclitaxel. ${ }^{34} \mathrm{With}$ GG genotype of CYP3A4 gene, decreased docetaxel clearance was seen compared to AA and AG genotype. ${ }^{32,35}$ In our study, OR was 2.26 (95\% CI: 1.03-4.94, P: 0.038) for patients with AA and AG genotype of CYP3A4: 392A $>$ G (CYP3A4*1B) gene: rs2740574 for grade $\geq 2$ neuropathy; however, OR was 0.64 (95\% CI: 0.37-1.10, P: 0.109) when it was evaluated with regard to the existing neuropathy.

It was shown that TT genotype of ABCB1 3435 was associated with a higher plasma concentration of docetaxel and longer overall survival (HR: 0.69, 95\% CI: 0.33-1.26, $P: 0.126)$ and more frequent side effects such as Grade 3-4 neutropenia, febrile neutropenia, and diarrhea when compared to patients with other genotypes. ${ }^{36}$ In another study, among patients who received paclitaxel, patients with the ABCB1 3435 CT genotype showed a tendency toward shorter overall survival than patients with the CC genotype (13.6 vs 18.5 months, $P$ : 0.06 ), but this association was not observed in the frequency of Grade 3-4 hematologic or nonhematologic toxicity with $3435 \mathrm{C}>\mathrm{T}$ genotype. ${ }^{37}$ In our study, grade $\geq 2$ neurotoxicity was more frequent in patients with TT genotype compared to TC/CC genotype (OR: 2.76, 95\% CI: 1.17-6.49, $P$ : 0.017).

It was found that FGFR4 gene, causing a transmembrane domain missense mutation (Gly388Arg), is associated with poor disease outcome in node-positive breast cancer, but it was not evaluated in relation to neurotoxicity. ${ }^{38}$ In our study, for FGFR4 gene with AG and GG genotype, an OR of 1.88 (95\% CI: 1.00-3.52, P: 0.048) was observed, compared to 
AA genotype, for any grade neuropathy risk. However, there was no statistically significant difference when evaluated according to grade. This is the first study analyzing the effects of FGFR4 gene for neurotoxicity risk.

The major limitation of this study is the retrospective design, the differences in the dose of paclitaxel used, and docetaxel treatment and schedule. The highlight of this study is the relationship between $A B C B 1$ and $C Y P 3 A 4$ genotype with grade of taxane-induced neurotoxicity. The varying results of the aforementioned studies regarding polymorphism may be due to the different ethnic backgrounds of selected patient groups. Breast cancer is an attractive area for study for clinicians, thanks to longer survival duration and considerable treatment response. Supportive care could be neglected because of overfocusing on the main treatment goal. However, adverse events of chemotherapy like neuropathy, especially grade $\geq 2$, are serious problems for breast cancer patients having such a long-term survival. This study showed that $A B C B 1$ and $C Y P 3 A 4$ could not predict Grade 1 neurotoxicity, which generally spontaneously recovers after chemotherapy; however, these genes can be used as a predictor of severe neurotoxicity, which has a permanent course and leads to a decreased quality of life, together with other risk factors such as DM duration before the decision of treatment.

\section{Conclusion}

ABCB1 3435 TT genotype and CYP3A4 392 AA and AG genotype may predict the risk of taxane-induced severe neurotoxicity.

\section{Disclosure}

The authors report no conflicts of interests in this work.

\section{References}

1. Huizing MT, Giaccone G, van Warmerdam LJ, et al. Pharmacokinetics of paclitaxel and carboplatin in a dose-escalating and dose-sequencing study in patients with non-small-cell lung cancer. The European Cancer Centre. J Clin Oncol. 1997;15:317-329.

2. Tran A, Jullien V, Alexandre J, et al. Pharmacokinetics and toxicity of docetaxel: role of CYP3A, MDR1, and GST polymorphisms. Clin Pharmacol Ther. 2006;79:570-580.

3. Marsh S, Somlo G, Li X, et al. Pharmacogenetic analysis of paclitaxel transport and metabolism genes in breast cancer. Pharmacogenomics $J$. 2007;7:362-365.

4. Marsh S, McLeod HL. Cancer pharmacogenetics. Br J Cancer. 2004;90: 8-11.

5. Evans WE, McLeod HL. Pharmacogenomics-drug disposition, drug targets, and side effects. N Engl J Med. 2003;348:538-549.

6. Henningsson A, Marsh S, Loos WJ, et al. Association of CYP2C8, CYP3A4, CYP3A5, and ABCB1 polymorphisms with the pharmacokinetics of paclitaxel. Clin Cancer Res. 2005;11:8097-8104.
7. Marsh S, Paul J, King CR, et al. Pharmacogenetic assessment of toxicity and outcome after platinum plus taxane chemotherapy in ovarian cancer: the Scottish Randomised Trial in Ovarian Cancer. J Clin Oncol. 2007;25: $4528-4535$.

8. Grau JJ, Caballero M, Campayo M, et al. Gene single nucleotide polymorphism accumulation improves survival in advanced head and neck cancer patients treated with weekly paclitaxel. Laryngoscope. 2009;119: 1484-1490.

9. Harris JW, Rahman A, Kim BR, et al. Metabolism of taxol by human hepatic microsomes and liver slices: participation of cytochrome P450 3A4 and an unknown P450 enzyme. Cancer Res. 1994;54: 4026-4035.

10. Rahman A, Korzekwa KR, Grogan J, et al. Selective biotransformation of taxol to 6 alpha-hydroxytaxol by human cytochrome P450 2 C8. Cancer Res. 1994;54:5543-5546.

11. Bosch TM, Huitema AD, Doodeman VD, et al. Pharmacogenetic screening of CYP3A and $\mathrm{ABCB} 1$ in relation to population pharmacokinetics of docetaxel. Clin Cancer Res. 2006;12:5786-5793.

12. Trock BJ, Leonessa F, Clarke R. Multidrug resistance in breast cancer: a meta-analysis of MDR1/gp170 expression and its possible functional significance. J Natl Cancer Inst. 1997;89:917-931.

13. Gréen H, Söderkvist P, Rosenberg P, et al. mdr-1 single nucleotide polymorphisms in ovarian cancer tissue: G2677T/A correlates with response to paclitaxel chemotherapy. Clin Cancer Res. 2006;12:854-859.

14. Tan SH, Lee SC, Goh BC, et al. Pharmacogenetics in breast cancer therapy. Clin Cancer Res. 2008;14:8027-8041.

15. Mielke S, Sparreboom A, Steinberg SM, et al. Association of paclitaxel pharmacokinetics with the development of peripheral neuropathy in patients with advanced cancer. Clin Cancer Res. 2005;11: 4843-4850.

16. Alsharedi M, Gress T, Dotson J, et al. Comparison of toxicity profile and tolerability between two standard of care paclitaxel-based adjuvant chemotherapy regimens in breast cancer. Med Oncol. 2016;16; 33(3):27.

17. Fountzilas G, Kalofonos HP, Dafni U, et al. Paclitaxel and epirubicin versus paclitaxel and carboplatin as first-line chemotherapy in patients with advanced breast cancer: a phase III study conducted by the Hellenic Cooperative Oncology Group. Ann Oncol. 2004;15: $1517-1526$.

18. Rowinsky EK, Donehower RC. Paclitaxel (taxol). NEngl J Med. 1995; 332:1004-1014.

19. Nabholtz JM, Gelmon K, Bontenbal M, et al. Multicenter, randomized comparative study of two doses of paclitaxel in patients with metastatic breast cancer. J Clin Oncol. 1996;14:1858-1867.

20. Lee JJ, Swain SM. Peripheral neuropathy induced by microtubulestabilizing agents. J Clin Oncol. 2006;24:1633-1642.

21. Chaudhry V, Chaudhry M, Crawford TO, et al. Toxic neuropathy in patients with pre-existing neuropathy. Neurology. 2003;60:337-340.

22. Miltenburg NC, Boogerd W. Chemotherapy-induced neuropathy: a comprehensive survey. Cancer Treat Rev. 2014;40:872-882.

23. Kus T, Aktas G, Kalender ME, et al. Taxane-induced peripheral sensorial neuropathy in cancer patients is associated with duration of diabetes mellitus: a single-center retrospective study. Support Care Cancer. 2016;24:1175-1179.

24. Hertz DL, Motsinger-Reif AA, Drobish A, et al. CYP2C8*3 predicts benefit/risk profile in breast cancer patients receiving neoadjuvant paclitaxel. Breast Cancer Res Treat. 2012;134:401-410.

25. Kalender ME, Demiryürek S, Oztuzcu S, et al. Association between the Thr431Asn polymorphism of the ROCK2 gene and risk of developing metastases of breast cancer. Oncol Res. 2010;18:583-591.

26. Hoffmeyer S, Burk O, von Richter O, et al. Functional polymorphisms of the human multidrug-resistance gene: multiple sequence variations and correlation of one allele with P-glycoprotein expression and activity in vivo. Proc Natl Acad Sci U S A. 2000;97:3473-3478.

27. Kim HJ, Im SA, Keam B, et al. ABCB1 polymorphism as prognostic factor in breast cancer patients treated with docetaxel and doxorubicin neoadjuvant chemotherapy. Cancer Sci. 2015;106:86-93. 
28. Bergmann TK, Brasch-Andersen C, Gréen H, et al. Impact of CYP2C8*3 on paclitaxel clearance: a population pharmacokinetic and pharmacogenomic study in 93 patients with ovarian cancer. Pharmacogenomics J. 2011;11:113-120.

29. Gréen H, Söderkvist P, Rosenberg P, et al. Pharmacogenetic studies of paclitaxel in the treatment of ovarian cancer. Basic Clin Pharmacol Toxicol. 2009;104:130-137.

30. Hertz DL, Roy S, Motsinger-Reif AA, et al. CYP2C8*3 increases risk of neuropathy in breast cancer patients treated with paclitaxel. Ann Oncol. 2013;24:1472-1478.

31. Leskelä S, Jara C, Leandro-García LJ, et al. Polymorphisms in cytochromes P450 2C8 and 3A5 are associated with paclitaxel neurotoxicity. Pharmacogenomics J. 2011;11:121-129.

32. Bosó V, Herrero MJ, Santaballa A, et al. SNPs and taxane toxicity in breast cancer patients. Pharmacogenomics. 2014;15:1845-1858.

33. de Graan AJ, Elens L, Sprowl JA, et al. CYP3A4*22 genotype and systemic exposure affect paclitaxel-induced neurotoxicity. Clin Cancer Res. 2013;19:3316-3324.
34. Apellániz-Ruiz M, Lee MY, Sánchez-Barroso L, et al. Whole-exome sequencing reveals defective CYP3A4 variants predictive of paclitaxel dose-limiting neuropathy. Clin Cancer Res. 2015;21:322-328.

35. Baker SD, Verweij J, Cusatis GA, et al. Pharmacogenetic pathway analysis of docetaxel elimination. Clin Pharmacol Ther. 2009;85: 155-163.

36. Tran A, Jullien V, Alexandre J, et al. Pharmacokinetics and toxicity of docetaxel: role of CYP3A, MDR1, and GST polymorphisms. Clin Pharmacol Ther. 2006;79:570-580.

37. Chang H, Rha SY, Jeung HC, et al. Association of the ABCB1 gene polymorphisms $2677 \mathrm{G}>\mathrm{T} / \mathrm{A}$ and $3435 \mathrm{C}>\mathrm{T}$ with clinical outcomes of paclitaxel monotherapy in metastatic breast cancer patients. Ann Oncol. 2009;20:272-277.

38. Thussbas C, Nahrig J, Streit S, et al. FGFR4 Arg388 allele is associated with resistance to adjuvant therapy in primary breast cancer. $J$ Clin Oncol. 2006;24:3747-3755.
OncoTargets and Therapy

\section{Publish your work in this journal}

OncoTargets and Therapy is an international, peer-reviewed, open access journal focusing on the pathological basis of all cancers, potential targets for therapy and treatment protocols employed to improve the management of cancer patients. The journal also focuses on the impact of management programs and new therapeutic agents and protocols on

\section{Dovepress}

patient perspectives such as quality of life, adherence and satisfaction. The manuscript management system is completely online and includes a very quick and fair peer-review system, which is all easy to use. Visit http://www.dovepress.com/testimonials.php to read real quotes from published authors. 